2008

\title{
Teacher Training: Creative Writing Instruction
}

Elizabeth A. Rice

Cedarville University

Follow this and additional works at: http://digitalcommons.cedarville.edu/education_theses

Part of the Elementary Education and Teaching Commons

\section{Recommended Citation}

Rice, Elizabeth A., "Teacher Training: Creative Writing Instruction" (2008). Master of Education Research Theses. 24.

http://digitalcommons.cedarville.edu/education_theses/24

This Thesis is brought to you for free and open access by 


\section{TEACHER TRAINING: CREATIVE WRITING INSTRUCTION}

A thesis project submitted in partial fulfillment of the requirements for the degree of Masters of Education

By

Elizabeth Aubrey Rice

B.A. Theology/Elementary Education, Appalachian Bible College, 2006 


\section{CEDARVILLE UNIVERSITY \\ SCHOOL OF GRADUATE STUDIES}

2008

I HEREBY RECOMMEND THAT THE THESIS PROJECT PREPARED UNDER MY SUPERVISION BY Elizabeth Aubrey Rice ENTITLED Teacher Training: Creative Writing Instruction BE ACCEPTED IN PARTIAL FULFILLMENT OF THE REQUIREMENTS FOR THE DEGREE OF Master of Education.
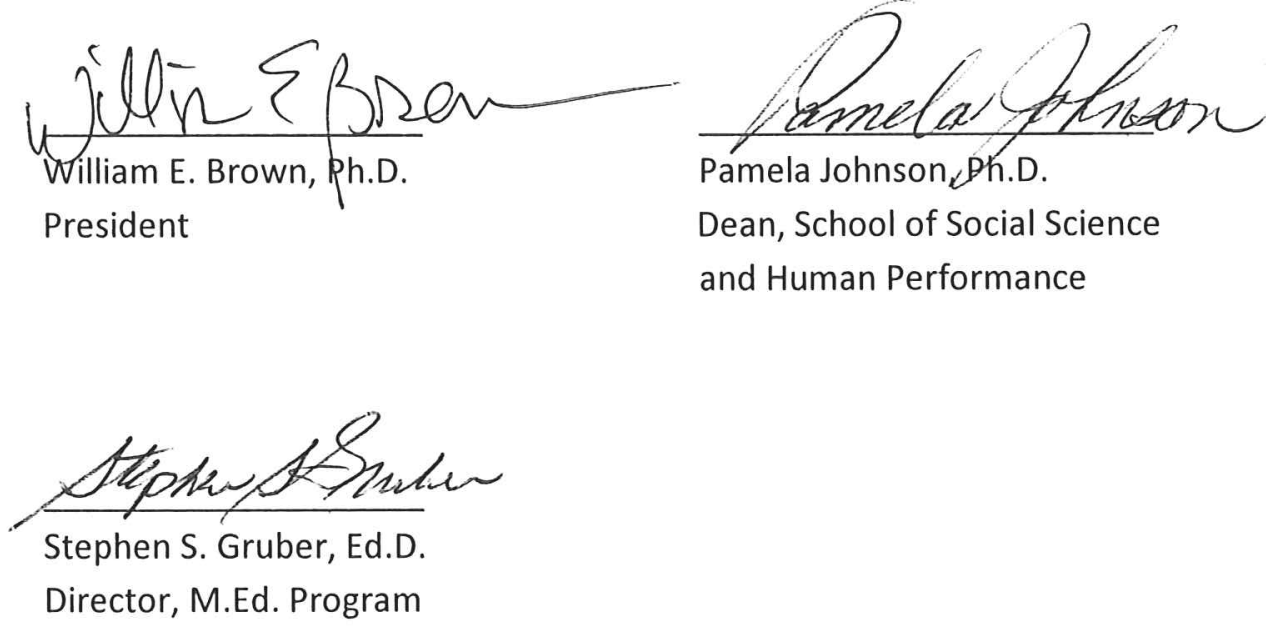


\begin{abstract}
Rice, Elizabeth A. Education Department, Cedarville University, 2008. Teacher Perceptions as it Pertains to Creative Writing Instruction

This thesis project consists of my design of a four-session teacher training in creative writing instruction within the elementary classroom setting. Oftentimes, teachers struggle with the implementation of creative writing instruction, as it is usually a task required of them in addition to their already overwhelming curriculum. My goal is to present practical strategies, methods, and ideas which teachers will be able to implement as they seek to challenge their students in the realm of creative writing.
\end{abstract}




\section{TABLE OF CONTENTS}

CHAPTER I: Introduction

Definition of Terms - 8

Statement of Issue - 9

Scope of the Project and Delimitations - 10

Significance of the Project - 11

Methods of Procedure - 12

CHAPTER II: Plenary Literature Review

Description of Creative Writing Instruction - 13

Benefits of Creative Writing Instruction - 13

Limitations and Barriers of Creative Writing Instruction - 15

Teacher Perceptions of Creative Writing Instruction - 17

Integration of Creative Writing Instruction - 19

CHAPTER III: Methods

Collection - 21

Implementation Procedure - 21

Organization - 22

CHAPTER IV: Project Findings

Key Themes - 23

Enhancing Instruction through Technology - 26

CHAPTER V: Discussion and Implications

Biblical Integration - 28

Strengths of the Project - 29

Limitation of the Project - 33

Suggestions for Future Research - 34

Potential Application - 34

REFERENCES - 36

APPENDICES

APPENDIX A: Teacher-Training Session Notes - 38

APPENDIX B: Power Point Presentations - 46

APPENDIX C: "Strategy Packets" \& Questionnaire - 58 


\section{ACKNOWLEDGEMENTS}

First and foremost, I give honor to my Lord and Savior Jesus Christ. Without Him, I am nothing.

I would also like to thank my parents for their consistent encouragement. Mom and Dad, thank you for the wings to fly! 
Chapter 1

Introduction

Writing has always been one of the most powerful forms of communication. However, even expert writers will struggle with effectively expressing their ideas. Zimmerman and Reisemberg (1997) explain that many students struggle with the writing process as it is oftentimes difficult to correctly plan, compose, evaluate, and revise their compositions. In response, the No Child Left Behind Act and the Individuals with Disabilities Education Improvement Act of 2004 mandate that teachers use researchvalidated practices to improve students' performance in all academic areas - including writing.

It is imperative for students to understand how to brainstorm and organize ideas in order to successfully create. In addition, they must be confident editors and revisers as they learn to become self-regulated writers. Many students who struggle with writing believe that good writing is related to form and mechanics only (Santangelo, 2005). Within the classroom, this often proves to be an issue that presents itself. Differences between skill-based and non-skilled based creative writing instruction provide teachers with an explanation of why there must be balance within the classroom (Seban, 2008). While it is necessary for students to grasp the mechanics of writing, they must also be given creative freedom to express themselves within a safe and nurturing environment. The master teacher provides this balance by integrating procedures and strategies from both learning perspectives (Pressley, 1996). Therefore, elementary teachers should embrace an eclectic approach when it comes to writing instruction. 
The role of the teacher is vital to successful creative writing instruction. There is a need for teachers to be actively involved in the writing process (Santangelo, 2008). Regular conference times, reflection periods, etc. must be an integral part of the student's writing experience. One of the major keys to student success is for the teacher to provide clear expectations. Norman (2005) believes creative writing to be a formable art in which all students are capable of participating rather than a talent that only a select few possess. Consistent guidance and encouragement from the teacher will provide all students with the confidence they need to succeed.

Differing perceptions of classroom teachers have been explored to bridge the perceptual gap and improve the status of important core subjects within the schools (Baker, 1996). Through this study, it was determined that students were more aware than one might think of their teacher's perceptions as it pertains to various areas of the curriculum. In comparing student and teacher attitudes, it was found that the subjects which teachers liked teaching were the subjects in which students enjoyed learning. Of the teachers and students interviewed, creative writing ranked high on both lists. This shows that teachers hold the key to students' attitudes toward school subjects because they, to a large extent, influence what happens in lessons, determine the content and teaching/learning processes and are responsible for the duration and placement of lessons in the daily timetable.

Graham (2001) found there to be considerable evidence that teachers' beliefs exert powerful influence on both teacher practice and student outcomes. Therefore, what teachers perceive as it pertains to writing instruction will directly influence their classroom practice related to the subject area. 


\section{Definition of Terms -}

Creative Writing - a form of writing focused on students' self-expression; an artistic form which draws on the imagination to convey meaning through the use of imagery, narrative, and drama. (Duke University - Writing Studio) Individuals with Disabilities Education Improvement Act of 2004 (IDEA) - a law ensuring services to children with disabilities throughout the nation (U.S. Department of Education)

No Child Left Behind (NCLB) - a governmental act focused upon raising student achievement, closing achievement gaps, and providing every child with a qualified teacher (National Education Association)

Non-Skilled Based Creative Writing Instruction - focuses on student creativity (Seban, 2008)

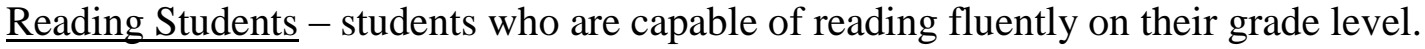

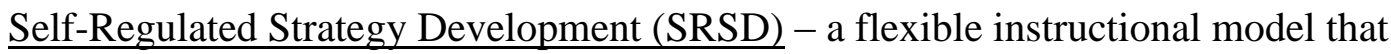
complies with No Child Left Behind by assisting students in explicitly learning the same kinds of planning, drafting, and revising strategies that are used by highly skilled writers. Santangelo (2008)

Skill-Based Creative Writing Instruction - focuses on the mechanics of writing (Seban, 2008)

Writing Workshop - interdisciplinary writing strategy which promotes student fluency in writing; includes continuous, repeated exposure to the writing process (Source for Learning) 


\section{Statement of Issue -}

While most educators would agree that reading and writing go hand-in-hand, it is clear that the art of writing often falls to the wayside as it pertains to writing instruction within the classroom. It has been suggested, there are seven reasons why children should write: 1) to entertain; 2) to foster artistic expression; 3) to explore the functions and values of writing; 4) to stimulate imagination; 5) to clarify thinking; 6) to search for identity; and 7) to learn to read and write (Tompkins, 1982). These reasons clearly suggest the importance of incorporating creative writing instruction into the regular classroom routine.

Unfortunately, many teachers feel as if they do not have the time to include creative writing instruction as they find their regular curriculum to be burdensome as it is. Manning (1995) encourages teachers to place writing at their top of their daily priority list. He promotes a regularly scheduled block of time for writing workshop, and discourages changes in such a schedule. It is imperative for teachers to understand that creative writing is not an extra subject to be tacked on at the end of the day. On the contrary, it is an art form that should be integrated across the curriculum. In addition, it is important to connect creative writing to all other academic disciplines (Marlow, 1995). Students must be able to transfer learned information from one situation to another.

Adding to the above mentioned concern, it seems that few teachers have received adequate training in creative writing instruction. As a result, many teachers find not only instruction, but also the grading of student work, to be nearly impossible. To exacerbate this problem, most language arts courses in general teacher education programs, simply include reading instruction with the writing component found to be of lesser importance. 
In response to such concerns, I desire to raise awareness in this specific area of education. I want teachers to become aware of their perceptions surrounding this topic as they serve as an example to their students. If they view the incorporation of creative writing as negative, I hope to make a positive influence by providing them with suggestions and creative strategies for successful creative writing instruction. I want to encourage teachers to attend creative writing workshops, related professional development seminars, etc. that will provide them with the tools necessary to correctly implement successful creative writing strategies. My challenge to them is that they seek to implement such strategies into their classroom routine in hopes that their overall perception of this realm of education will change for the better. This will, in turn, assist in producing students who are confident, excellent writers. As an educator, this is, indeed, the overall goal.

Scope of the Project and Delimitations -

In this project, I will include creative strategies that I have found to be successful within the elementary classroom setting. Throughout the training sessions, I seek to address teacher perceptions of the benefits and limitations of implementing creative writing instruction into their classroom, and I also plan to give participants an opportunity to elaborate concerning related instructional methods which they have found to be successful within the walls of their classroom. These will be the constructs upon which I will focus. As a result of such interaction, it will become increasingly clear as to what types of instructional strategies successful creative writing teachers are implementing. 
For this particular project, I will specifically focus on general education classroom teachers in grades 2-4. I do not intend to differentiate between public school and private school classroom settings.

In the future, I foresee conducting further compilation in this area. Further research may include focused interviews with general education classroom teachers on various grade levels. An interesting study may include a comparison of elementary teachers with secondary and/or college level teachers.

\section{Significance of the Project -}

I foresee the compilation of this project as proving beneficial in a number of ways. My initial aim is to raise awareness in the minds of teachers as to what their perceptions are pertaining to the realm of creative writing instruction. If their views are positive, I hope to gather any successful strategies they may have and share them with other teachers who may benefit. If their views are negative, on the other hand, I desire not only to encourage them in this area but to also provide them with ways to make this type of instruction a more "comfortable fit" for them in their classroom. In the end, my primary aim is to assist teachers by providing them with new ideas that will aid them in the successful integration of creative writing across their curriculum. 


\section{Methods of Procedure -}

The initial step, as I seek to carry out this compilation, is to spend a vast amount of time researching/gathering numerous creative writing strategies, methods, ideas, etc. After doing so, I will spend several weeks attempting to incorporate the found methods into my own creative writing instruction. After some weeks, I will then begin to organize my successes into a four-session creative writing teacher-training seminar. My materials will include the following: power point presentations (one per session) as well as "strategy packets" which are intended to be distributed to each seminar attendee. The packet will include a brief questionnaire which will not only assess whether or not awareness was raised, but it will also allow participants to share their desires concerning the implementation, if any, of the new ideas provided within the training sessions and/or "strategy packets". I will ask for these questionnaires to be completed and returned to me following one's attendance to the seminar(s).

An incentive will be provided for each teacher who not only completes and returns the questionnaire but who [within the next thirty days] implements at least one new creative writing technique into their instruction. Upon the completion of doing so, they must e-mail me personally and describe not only the strategy that was carried out but also the result of their doing so.

Teachers with negative perceptions may not be as likely to implement new strategies. Even with offered incentives, they may not be willing to "take the time" or "go the extra mile" in order to stretch themselves concerning this issue. Therefore, I realize that my questionnaire feedback may not be as rich as I anticipate. 


\section{Chapter Two}

Plenary Literature Review

\section{Description of Creative Writing Instruction -}

Creative Writing truly is an art form that teachers must whole-heartedly seek to impart to their students. It plays an important role in a child's literacy development. Just as basic phonemic skills are mastered and built upon in order to challenge students in the area of reading, basic composition skills, as well, must be obtained and developed as students mature into competent, creative writers. The writing process includes basic steps that students are expected to carry out in order to successfully publish their written work: Plan, Compose, Evaluate, and Revise. However, in addition to completing such a list of basic tasks, students must also learn how to "tap in to" an exciting world of creativity where in which they understand the art of elaborating through language/vocabulary, content, theme, imagery, and more.

\section{Benefits of Creative Writing Instruction -}

All human beings desire a sense of ownership when it comes to their creative work. Therefore, writing can be one of the most deeply satisfying acts as it gives the author the opportunity to exhibit such ownership. It also provides the author with an outlet for creativity and personal expression - a chance to learn about who they are as an individual. Although students will not always have the opportunity to write about things that interest them, when at all possible, writing instructors must allow this to be the case as a means instilling within the student a motivation to write (Urquhart, 2005). Writing can be described as an activity that is both exciting as well as enriching (Martin, 2001). 
Writing teaches kids critical thinking and organizational skills that carry over to every other subject (Schrecengost, 2001). Planning is a key component in the writing process. As the student learns to organize their thoughts carefully, and then elaborate creatively, they embark on an incredible adventure known as the writing process.

Writing can also be described as as a communication vehicle, an assessment tool, and an intellectual exercise that benefits both the teacher and the student (Urquhart, 2005). Through writing, the teacher gets to know her students, what they are thinking, and what they are (or are not) learning. On the other hand, the student is given an opportunity to think about their thoughts, record them on paper, and reflect on their presentation of knowledge. Interacting with students as they write provides teachers with prime opportunities for praising students. Writing instructors must be quick to encourage positive aspects of of student work. While weaknesses must be pointed out, educators must be careful in how they do so.

There are many added benefits of getting parents involved in the creative writing process (Tompkins, 1982). By doing so, through a variety of creative avenues, an additional measure of support is added within the teaching/learning community.

Students must understand that a strong writing ability will not only aid them throughout their years of schooling, but it will also be a vital asset in the work place. Being able to write well is more important than ever - regardless of one's field (Urquhart, 2005). Writing students must be made aware of the long-term goals and benefits involved in this process. 


\section{Limitations and Barriers of Creative Writing Instruction-}

As a general education classroom teacher, it can be difficult to manage students as they each tend to be at different levels in their writing development. It is helpful to understand what students mastered in the previous years(s) as well as what they will be expected to do the following year(s). Closing the achievement gap in this area is difficult, but it can be done (Seban, 2008).

Schrecengost describes creative writing as a "craft". She encourages teachers to impart skills and techniques for students to learn and practice in order for them to become writing whizzes. "What is required?" she asks. Time! Consistent practice over long periods of time is absolutely necessary in order for students to develop as writers.

Most teachers would agree that one of the greatest limitations pertaining to creative writing instruction is that of time. It is often difficult for educators to keep up with their curriculum demands much less include any additional instructional periods. However, creative writing instruction must not only be included in the day-to-day classroom routine, but ample time must be provided as students learn to reflect, edit, and review their publications. Schrecengost (2001) would argue that teachers don't have time to not teach writing. He expresses the concern that in some classrooms, writing is treated as an "extra" - as something to fit in if time permits or as a 'fill-in' activity when there's time left over. This approach serves only to convey the dreadful message that 'writing isn't important'. Urquhart challenges teachers to view creative writing as an opportunity for students to utilize problem solving skills. Therefore, should not teachers hold this activity in high esteem - giving it first place in the classroom? 
Teachers should consistently arrange their days so that a large block of time is allotted for "writing workshop" (Manning, 1995). She explains that many colleagues will not understand why you lack flexibility in this area, but proceeds with such an emphasis as to encourage teachers that it will not be long before obvious benefits from such a schedule become evident. Unfortunately, statistics show many American students as being incompetent in the area of writing (Urquhart, 2005). However, she believes that with simply more opportunities to write, we will begin to see a dramatic increase in student writing capabilities.

Walker (1996) provides carefully thought out guidelines for teachers who desire to present beneficial creative writing lessons that stay on course. She explains that there are as many ways to teach writing as there are writers, but if we aren't careful, some practices may dissuade young writers and devalue writing classes. We must be ever mindful to present clear expectations for students as we guide them through their writing experiences. Without such guidance from the teacher, students will struggle with gaining confidence as a writer (Norman, 2005).

In seeking to set forth and abide by set guidelines, the importance of consistency must also be addressed as it pertains to grading. Many teachers feel that the evaluation of creative writing is subjective. However, it is possible to fairly judge student progress based on practical criteria for assessment. Such criteria should be based on student writing skills - focusing on organization, punctuation, etc. Glazer includes the explanation that it can be tailored to specific student strengths and weaknesses, and should be modified for the individual child as their abilities develop. 
While it is imperative for students to be given opportunities to work together on their publications, teachers must consider the importance of establishing and maintaining consistent classroom management strategies in order for collaborative "writing workshops" to truly be a success.

Teachers must be aware that there is much to consider as they embark on their attempt to assist students in becoming competent writers. Zimmerman (1997) recognizes the related frustration of many students, while furthermore acknowledging the need for struggling students to have competent instructors who are adequately prepared for the task at hand. This may require that they participate in related training or professional development courses that will assist them in confidently imparting such knowledge to their students.

\section{Teacher Perceptions of Creative Writing Instruction-}

Other than writing e-mail messages, letters, memos, and, of course, never-ending lesson plans, most teachers, themselves, are not writers (Schrecengost, 2001). This may be why many teachers find the task of creative writing instruction daunting. Schrecengost's book is especially geared toward teachers who feel this way - teachers who may have never, themselves, been exposed to writing instruction beyong that for preparing for college papers.

In Graham's article concerning teachers' theoretical orientations about writing instruction, he explains that if teachers possess a passion for creative writing, the evidence will show forth in their practices as well as in student outcomes. This means that such a passion would prove beneficial within the writing classroom or if such passion 
is absent or lacking, the results would, in turn, be negative. Classroom environments that are supportive, pleasant, and non-threatening develop students' passion for writing and increase the likelihood that students will apply the strategies they have learned. This is particularly important for students who struggle with writing as many of them must overcome the lingering effects of previous experiences where they felt unsuccessful and frustrated throughout the writing process.

It must be understood that creativity is not dependent on personality types - even though certain personalities are more prone to use such methods with ease (Simplicio, 1999). If creativity can be studied and better understood and if its guiding principles can be identified and duplicated and then taught to others, then all teachers can be given an invaluable tool that will bring their classrooms to life. Simplicio encourages teachers to, first of all, exhibit willingness for change and then spend their time looking for and utilizing any and all sources that will assist them in imparting knowledge to their students.

The sobering aspect of Graham's findings is that teachers' perceptions directly effect students' perceptions. Therefore, careful consideration must be given to this - as well as all - method(s) of instruction as the perspective of the child is, to a certain extent, "controlled" by the teacher.

Throughout my research, it became increasingly clear that creativity does not lie solely in the teacher or in the students' perceptions, but in the interaction between the two. In the educational setting, an environment that fosters creativity must include the following components: allowing time for creative thinking; rewarding creative ideas and products; encouraging sensible risks; allowing mistakes; imagining other viewpoints; 
exploring the environment; and thinking about the thinking process (Fleith, 2000). Flieth describes the common misconception concerning young children's inability to think productively has led to an overemphasis upon recall and reproduction to the neglect of creative thinking.

\section{Integration of Creative Writing Instruction -}

Writing is a powerful tool for thinking and learning - so powerful that it should not be limited to the writing workshop. Students must have opportunities throughout the day to engage in writing. Improving writing is not the major purpose for incorporating writing in various curriculum areas. Manning believes that the major purpose is to help students clarify and extend their knowledge in specific content areas. She explains two general ways in which writing can be integrated into various content areas. She describes a "Content Journal" as an opportunity for students to review or interpret learned information. Questions such as, "What did you learn today?" or "What did we discuss in class today that you would like to understand better?" can be used to build upon content knowledge. She also has found that "Written Conversations" between/among students are beneficial in the sense that students are given the opportunity to answer each other's content questions in the form of written communication. It is as if a classroom discussion were taking place on paper. Yes, these types of activities take time, but time must be allotted if successful integration is to take place "across the curriculum". Being able to process information in print, reorganize information, and express understandings with clarity in one's own language is a necessary skill in all subject areas (Schrecengost, 2001). 
Ediger expresses concern toward a "separated-subject" approach. A major problem of separate-subjects curriculum is whether or not students will be able to transfer what has been learned from one situation to another. He is an advocate for "fused curriculum" - where listening, reading, and writing are all parts of the learning process. He includes an emphasis on critical as well as creative thinking and urges teachers to present their students with opportunities to think in such a way. 


\section{Chapter Three \\ Methods}

\section{Collection -}

As a means of collection, time was spent gathering/reviewing a wide variety of creative writing strategies, methods, ideas, etc. Resources included manuals, books, periodicals, on-line resources, colleagues, as well as my own personal portfolio and file cabinet. In speaking with follow elementary teachers (grades 2-4), I began to gain a sense of the variety of perceptions/perspectives related to my topic. As a result, I found myself increasingly passionate as I sought to create a product that would not only raise awareness concerning the need for better creative writing instruction, but would also provide educators with practical teaching strategies and techniques related to creative writing instruction.

\section{Implementation Procedure -}

As an elementary classroom teacher, I was able to conveniently implement many of my new-found techniques which I came across during my time of research. I spent several weeks incorporating creative writing mini-lessons, "Writing Workshops", etc in to my regular classroom routine. A special emphasis was placed upon integrating creative writing strategies across-the-curriculum. In addition to the strategies discovered during my recent research, I also pulled from experiences found to be successful in previous years of teaching. I paid careful attention to student, as well as parent reactions and responses. 


\section{Organization -}

After some weeks, I began to organize my successes into a four-session creative writing teacher-training seminar. The materials produced include the following: training session notes, power point presentations (one per session), and "strategy packets" which would be distributed to each seminar attendee. 


\section{Chapter Four}

Project Findings

\section{Key Themes-}

Throughout the compilation of this project, it was clear - time and time again that creative writing instructors must reach out to all learning levels as well as learning styles - as should all educators. Students must "come to the table" ready to write - They must come with interests and ideas which will be useful in the creative writing process. Without such contributions, they lack the needed readiness. Therefore, teachers must be prepared to deal with students who need a little extra "push" in this area. Get the students talking! What is their background? What are their likes/dislikes? Include opportunities for them to use their imagination orally in hopes that they might be able to share these same thoughts in creative written form.

Howard Gardner's Multiple Intelligences summarizes the differences in learning styles. Such variances must not be ignored - even when teaching creative writing. All students learn and interact with knowledge differently. In response, the writing teacher must be aware of this instructional component, and it is vital that a variety of techniques/strategies be used within the classroom in order to accomplish the overall goal - imparting to all the skills necessary to bloom as a writer.

Over the past months, I have worked to implement a number of specific assessment techniques which I anticipated as proving beneficial to my creative writing students. The following evaluations were completed as an opportunity for me to assess how beneficial these strategies had actually proven to be. 
Name

Student Evaluation

Not Very

Beneficial

Self Evaluation Checklist

Writing Journal Portfolio

Student-Teacher Conference

Peer-to-Peer Conference
1 pt.

$1 \mathrm{pt}$.

$1 \mathrm{pt}$.

$1 \mathrm{pt}$.
Beneficial

2 pts.

2 pts.

2 pts.

2 pts.

Teacher Evaluation [of student]

Name

Not Very

Beneficial

Self Evaluation Checklist

Writing Journal Portfolio

Student-Teacher Conference

Peer-to-Peer Conference
$1 \mathrm{pt}$.

$1 \mathrm{pt}$.

1 pt.

$1 \mathrm{pt}$.

\section{Beneficial}

2 pts.

2 pts.

2 pts.

2 pts.
Very Beneficial

3 pts.

3 pts.

3 pts.

3 pts.
Very Beneficial

3 pts.

3 pts.

3 pts.

3 pts. 
The following chart displays the students' assessments vs. my assessments of each one of them as it pertains to whether or not the strategies listed were deemed beneficial to them.

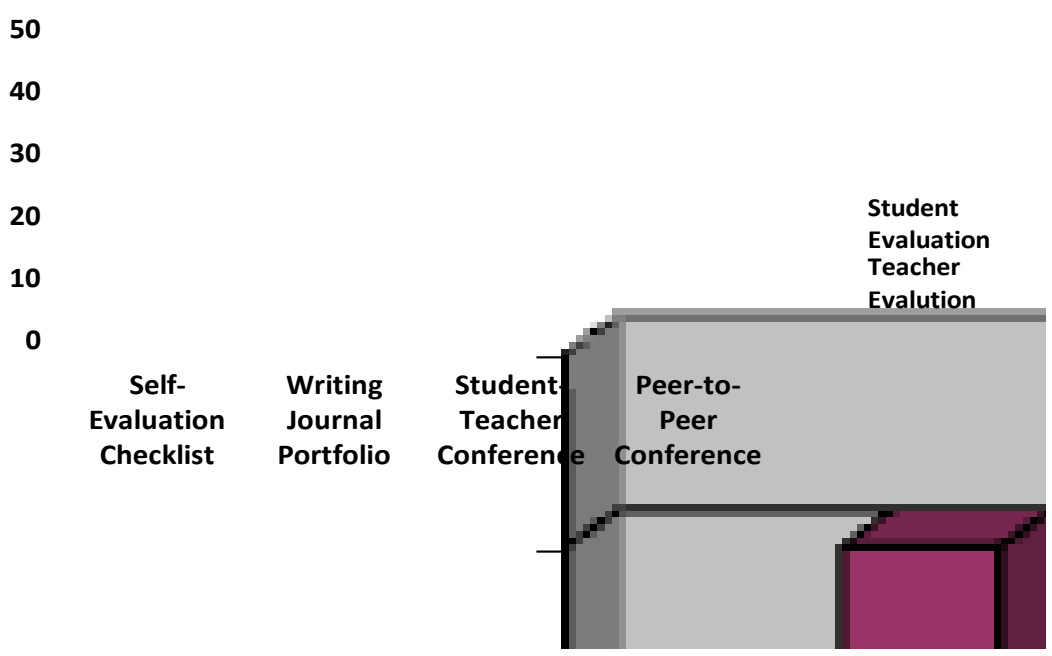

Through the analysis of this data, it is evident [to me as the classroom teacher] that the learning styles as well as personality traits of each of my students are represented in these results. Therefore, these comparisons may look quite different for another group of students.

It appears that the widest discrepancy in perceptions pertains to the benefits of the "Self-Evaluation Checklist". As I consider this finding, I cannot help but ask the following questions. "Do the students view the checklist as 'more work'?" "Is there a way for me to make the checklist more 'attractive' to them?" "As a whole, are my thirdgraders developmentally prepared to understand the benefits of taking a second, third, and even fourth glance at their work?" "How much of a student's personality plays into whether or not they find this tool helpful in producing quality work?" 
Throughout the weeks of implementation, two very interesting factors grew increasingly clear. The students excitement about their creative writing opportunities heightened while, for the most part, parents remained fixed on the idea that creative writing is not quite as important as what they would consider to be core subjects such as math, science, etc. I quickly came to the realization that it is going to be of utmost importance for me to research and then implement ideas that will ignite enthusiasm in the parents as I continue to stress the value and importance of writing creatively. Immediately, I considered the need for a discussion of students' written work to be a key part of general parent-teacher conferences. I also entertained the idea of holding a "Creative Writing Night". I foresee such an event being successful simply based on the fact that students would be excited about their work, which would result in them begging their parents not to miss the special evening at school. What a great way to strengthen the learning community bond!

\section{Enhancing Instruction through Technology-}

One of the most obvious ways in which creative writing instruction can be enhanced is through that of technology. Such enhancements are described below:

- Differentiate by allowing students who struggle with "pencil-and-paper" to utilize a word-processing program in which to type

- Use word-processing program features to teach students the following:

- How to create an outline (automatic formatting components)

○ How to edit/revise (cut, copy, paste, etc)

- Provide students with the following on-line resources 
- Search Engines to assist with Brainstorming

○ Dictionary (Language Enrichment)

○ Thesaurus (Vocabulary Enrichment)

- Allow students to interact with publishing programs as they learn to create a variety of written works

- Online collaborative writing projects with other students their age (cross-cultural activity if at all possible)

Technology is the key to enriching a student's learning experience in all content areas - from fine arts to mathematics - including creative writing (Urquhart, 2005). Urquhart believes technology to be the most valuable classroom tool, and she expresses the idea that we have come to a point where technology has forever altered teaching and learning in ways that were once unimaginable. 


\section{Chapter Five \\ Discussion and Implications}

\section{Biblical Integration-}

As the Christian attempts to live a godly life in this world, he must understand the need for a well-rounded education. Luke 2:40 says, "And the child grew, and waxed strong in spirit, filled with wisdom: and the grace of God was upon him." The Bible, numerous times, encourages one's need for wisdom through education.

The unregenerate man is in need of training that will lead Him to know the God of the Bible and the everlasting life that is available through the Savior. On the other hand, the Christian is in need of an education that will provide Him with the wherewithal to live a life that is pleasing to His Savior. This means that the Christian should be trained to do His very best in all aspects of life and study. Therefore, true education must be centered upon God's Word. This does not mean that the Bible will be the sole textbook for all matters of study. However, the truths of God's Word can easily be applied to all aspects of education. God's holiness and perfect exactness can be demonstrated through the mastery of grammatical and mechanical writing skills. As related to writing, the Creator's longing for organization is evident in I Corinthians 14:40 when He commands "all things to be done decently and in order." Such principles are easily applied to creative writing.

God desires that His children be eloquent communicators orally as well as in written word. Only then are we truly able to successfully share His Word with others. God is a God of variety. Therefore, he values creativity. He expects students as well as educators alike to appreciate differences and variances among his creation. He appreciates strong supporting details, colorful vocabulary, descriptive phases, etc as He, 
Himself, spoke the Scriptures in like manner. God is a God of excellence. Therefore, form and mechanics must not be ignored. He desires that his creation be excellent minded. In all areas of curricula, it is imperative for students to gain strength in the areas of critical thinking and problem solving.

The writing instructor has the responsibility of carefully guiding students through the writing process. The concept of "guiding" is a Biblical concept. Scripture speaks of the danger of "leaving children to themselves" (Proverbs 29:15). Therefore, what better way to teach than through "guiding"? In order for a guide to truly be successful, they, themselves, must be sufficiently trained and prepared for their duty. (II Timothy 2:15) It must be understood that this training is an on-going process, and creative writing instructors must realize that there is always something new to learn. The master teacher will be hungry for new knowledge in order to transmit it appropriately to his students.

\section{Strengths of the Project-}

Creative writing instruction has always been one of utmost importance to me as a teacher. I have consistently felt compelled to train students in this particular area of instruction. However, there have often been times when I felt frustrated with my students as we worked together in completing the writing process. Throughout the compilation of this project, I have come to the realization that much of my frustration stemmed from the following two issues: I was not providing my students with ample time to thoroughly carry out the creative writing process and I was not presenting clear guidelines and expectations as to what was required of them. I have been challenged to plan my time 
more carefully and organize/carry out my classroom practices in a more thoughtful manner.

The information presented within this project has been designed to use with flexibility. While, at this time, I have not yet had the opportunity to present the enclosed teaching training sessions at a seminar/conference, I did assemble five peer educators with whom I discussed my project and project findings. This group included three thirdgrade teachers, one kindergarten teacher, and one pre-school teacher. Prior to our meeting, each attendee completed the following questionnaire:

Your Name

Grade Level

Number of Years Spent Teaching in the Elementary Classroom

In the space below, please describe what you believe to be the benefits of students writing creatively.

What is your current practice as it relates to creative writing instruction? (Feel free to include specific strategies that have been successful in your classroom.)

As a classroom teacher, have you experienced any specific struggles related to creative writing instruction? If so, please explain.

In what ways might you seek to improve your creative writing instructional practices? 
As we discussed strategies/techniques that I have found to be successful in my classroom, the third-grade teachers became very interested in my "unit approach" to teaching - a methodology where creative writing can easily be incorporated across the curriculum. One of these teachers was quoted as saying, "Wow! I have never thought of doing it differently!" and she immediately began to brainstorm ways in which she could include creative writing in her current Civil War unit. "Imagine that you are soldier fighting in the Civil War. Write a letter home to your family telling them all about the most recent events. You may choose to be a soldier fighting for the north or the south." Another third-grade teacher brought up the fact that approaching curriculum in this manner would be an incredible "time saver". The conversation continued to unfold as we discussed the negative implications of teaching subject-by-subject as opposed to delving into unit studies where all areas of curricula are integrated. However, this same teacher expressed concern as to how she would be able to change her approach this late in the school year. While she showed an interest in the ideas being presented, she was obviously uneasy as to how one might go about the implementation process. It was interesting to me to note that she was the one [in this particular group] that had been teaching the longest. It seemed that the other four teachers (who are all in their first three years of teaching) were more open to jump "head-first" into trying something new.

The kindergarten and pre-school teachers who were present had both had the opportunity to observe in my creative writing classroom. The following is an observational statement from the kindergarten teacher: "I watched Miss Rice start the day and transition her students into the guided writing activity. As the students' inspiration for writing, Miss Rice placed pictures of seasonal scenery on the board. Miss Rice 
provided the students with clear steps to follow in their writing (Plan-Compose-EvaluateRevise) and a checklist for the students to use to evaluate their work. Miss Rice and I discussed the importance of varied forms of assessment (veering away from the traditional 'pencil-and-paper' way of 'grading' students). We challenged each other to continue to grow in this area of teaching."

The pre-school teacher was quick to consider ways in each a number of these strategies could be adapted to fit the grade level of her students. In addition, she provided the whole group with ideas as to how these techniques could be "taken a step further" and made to be even more "hands-on" and creative. I appreciated her perspective, and I believe the entire group benefitted from our time together.

Following our meeting, each attendee completed the following questionnaire: Your Name Grade Level Number of Years Spent Teaching in the Elementary Classroom

As an educator, did your perception(s) of creative writing instruction change as a result of this session? ---If so, in what way?

What practical strategies did you gain from your attendance to this seminar?

Do you intend to utilize any of these new ideas into your classroom instruction? 
If so, please describe your plan for implementation?

As mentioned above, the majority of the peers with which I met were fairly new elementary classroom teachers - such as myself. As I reviewed the questionnaires and reflected upon our whole-group discussion, I recognized that the newer teachers seemed to place a greater emphasis on the importance of creative writing in the elementary classroom. Each one seemed interested in implementing a variety of new ideas into their set curriculum. The more "seasoned teacher", however, was more hesitant. I cannot help but wonder why her perception of creative writing instruction seems to differ from that of the others in the group. I imagine that her educational training varied in some aspects; Her past experience(s) would also play a role in her present attitude; and in working with her on a daily basis, her approach to teaching could be described as more "by the book" than that of creative.

\section{Limitations of the Project-}

It would be unrealistic to think that any one person could address all aspects of any one topic. Therefore, I realize that my particular project only focuses on some of what I believe to be the key issues related to creative writing instruction. I also understand my project includes techniques and strategies that have proven successful for me personally within the walls of my own classroom. Others may find some of my ideas to be less than suitable for them as their style of teaching, classroom setting, etc may differ. 
While this thesis project provides general education classroom teachers (grades 24) with an overwhelming supply of instructional ideas related to creative writing, early childhood educators as well as secondary level teachers may find my compilation to be of little use as this project focuses mainly on primary level students.

\section{Suggestions for Future Research-}

In the future, I foresee conducting further research in this area. I plan to continue growing my personal collection of strategies/ideas as well as my professional portfolio of successfully implemented techniques. Further research may include focused interviews with regular classroom teachers on varying educational levels (secondary, college, graduate, etc.)

\section{Potential Application-}

The application of the thoughts/ideas set forth within this thesis project could be found useful in a variety of different ways. First of all, I look forward to honing my presentation of many of the instructional strategies found throughout this assemblage. I am interested to see how students - in the coming years - react to many of the strategies with which I have had previous success.

Secondly, I foresee this project as being an incredible product which to place in my professional portfolio. If at any point, I am called upon to speak at a conference or convention, I feel that my planned session(s) would benefit any teacher with a passion for enhancing the classroom. 
Appendices

Appendix A: Teacher-Training Session Notes

Appendix B: Power Point Presentation

Appendix C: "Strategy Packet” \& Questionnaire 


\section{References}

Burke, Kay. (2005). How to assess authentic learning. Thousand Oaks, CA: Corwin Press

Duke University. (2008). Writing workshop. Retrieved July 16, 2008 from http://uwp.aas.duke.edu/wstudio/resources/genres/creative_writ.pdf

Glazer, S. (1994). Collaborating with children to assess writing objectively. Teaching K-8, 24(5), 108-109 [EJ 476 516]

Graham, S. (2001). Primary grade teachers' theoretical orientations concerning writing instruction: Construct validation and a nationwide survey. Contemporary Educational Psychology, 27 , 147-166.

Fleith, D. (2000). Teacher and student perceptions of creativity in the classroom environment. Retrieved June 19, 2008. Education Research Complete.

Manning, M. (1995). The writing process classroom. Teaching PreK-8, 25, 84-89

Marlow, E. (1995). Integration of content in the language arts. Journal of Instructional Psychology, 22(2), 127-129

Martin, J. (2001). Writing prompts. Jefferson City, MO: Scholastic Professional Books National Education Association. (2008). No child left behind. Retrieved July 16, 2008 from http://www.nea.org/esea/nclbstories/index.html?source=google $\&$ gclid=CMPE6f3OxZQCFQvOIgodewSvXg

Norman, K. (2005). Our lives as writers: examing preservice teachers' experiences and beliefs about the nature of writing and writing instruction. Teacher Education Quarterly, 32(1), 25-40.

Pressley, M. (1996). A survey of instructional practices of primary teachers nominated as effective in promoting literacy. Elementary School Journal, 96, 363-384. 
Schrecengost, M. (2001). Writing whizardry.

Seban, D. (2008). A look within individual cases into elementary teachers' beliefs and practices of writing instruction. Elementary Education, 7(2), 512-521.

Santangelo, T. (2008). Using self-regulated strategy development to support students who dave "Trubol Giting Thangs Into Werds." Remedial and Special Education, 29(2), $78-87$

Simplicio, J. (1999). Teaching classroom educators how to be more effective and creative teachers. Retrieved June 19, 2008. Education Research Complete.

Source for Learning - Teachers first. (2008). Retrieved July 16, 2008 from http://www.teachersfirst.com/lessons/writers/

Tompkins, G. (1982). Seven reasons why children should write stories. Language Arts, 59(7), 718-721.

Urquhart, V. (2005). Teaching writing in the content areas. Alexandria, VA: ASCD

U.S. Department of Education. (2008). IDEA. Retrieved July 16, 2008 from http://idea.ed.gov/

Walker, N. (1996). Teaching Writing. Teaching Pre K-8. v.26, 50-51

Zimmerman, B., \& Reisemberg, R. (1997). Becoming a self-regulated writer: A social cognitive perspective. Contemporary Education Psychology, 22, 73-101 


\title{
APPENDIX A \\ TEACHER-TRAINING SESSION NOTES
}

\author{
Session One - Teachers' Perceptions of Creative Writing Instruction
}

Anticipatory Set:

Capture their attention through the means of children's literature by reading an appropriate book aloud to the seminar attendees.

(Ex. "Mrs. McBloom, Clean Up Your Classroom")

Explain that reading to students provides them with experiences that will aid them in understanding what to write about and how to successfully express themselves through this form of communication.

Emphasis the importance of asking learners the following types of questions:

- Who is this story about?

- What do you know about the character(s)?

- Where did the story take place?

- What was the main event in the story?

- How did the story end?

Key Points:

Teachers' perceptions of creative writing instruction directly effect students' perceptions as well as student outcomes. Teachers must get excited about the responsibility they have to encourage students in the area of creative writing.

Strategies/Techniques to Discuss:

- Always make time for writing. Do not ever treat it as an "extra".

- Establish an exciting mood during writing time.

- Model strong creative writing skills. Teachers must also be open, honest, and "real" in their writing if they expect their students to do the same. Creative writing instructors should write-along as their students write. What a wonderful example this is for students!

- Expose students to all genres of writing. Assist them in becoming comfortable with varying styles.

- Provide the students with opportunities to write as a group. Their enthusiasm will be contagious. (Students must be taught to value and respect individual differences.)

- Portfolios - Provide each child with a portfolio (folder, box, etc.) in which to keep their published works. As this collection builds, so will their confidence as they begin to understand that you value their creative work.

- Invite a published author to join the class and share their product(s) with the students. 
- Portfolio Parent Conference - (These can be held during school hours or in the evenings.) Parents are given the opportunity [quarterly or semesterly] to come in and spend time conferencing with their own child - paying close attention to their creative growth .

- Designate a bulletin board on which student work can be displayed. Young writers will feel a great deal of pride as they see their efforts earning recognition.

Resources Available:

The Book of Reading and Writing by Sandra Anderson - Corwin Press (2003)

The Jumbo Book of Writing Lessons by Teacher Created Resources (2004) 
Session Two - The Writing Process (Plan, Compose, Evaluate, and Revise)

Anticipatory Set:

"Would you take a trip without first planning your route? Would you leave without packing your necessities? If on your trip, you encountered a delay, a detour, or construction, would there be changes made to your plans?"

Key Points:

What is a "writing workshop"? - It is an interdisciplinary writing strategy which promotes student fluency in writing; includes continuous, repeated exposure to the writing process.

What does it mean to plan? (Prewriting) - Think of subjects to write about (brainstorm). Choose the best one. List a variety of ideas about your subject.

What does it mean to compose? (Drafting) Write about your chosen topic. Always include a beginning, middle, and ending (organize). This step is considered the first draft.

What does it mean to evaluate? Read over your writing and/or have someone else read it.

What does it mean to revise? (Editing) Make any necessary changes - Check spelling, grammar, capital letters, and punctuation. Then, publish your corrected final draft. (Publishing)

Strategies/Techniques to Discuss:

1. Plan

a. Brainstorming

- Idea Basket - Fill a small basket with a variety of items. This could be a themed basket or it could include a wide range of random objects. Instruct each student to choose one item from the basket and write about it.

- Subject Jar - Fill a jar with strips of paper that include a variety of different things that have to do with a particular topic. For example, if the topic is "winter", the strips will say things like "snowman", "chicken noodle soup", "polar bear", mittens", etc. Allow students to pull a strip from the jar and write a descriptive paragraph about their chosen object.

- Story Starters - Writing prompts provide students with interesting ideas as a means of getting their creative juices flowing.

- Picture Prompts - Display a random picture/photograph, and instruct the students to create a story about the picture. 
- Free Writing - Allowing students to write freely about a particular topic provides them with an incredible opportunity to brainstorm. Mechanics should not to be the focus during "free writing".

b. Organizing

- Hamburger Writing - Top Bun (Beginning/Topic Sentence); Meat (Middle/Supporting Detail Sentences); and Bottom Bun (Ending/Conclusion Sentence)

- Write a Story 1, 2,3 - Paragraph One includes the characters and the setting (Who? Where? When?). Paragraph Two includes the action (What happened?). Paragraph Three includes the conclusion (What happened last? How did the story end?)

- Graphic Organizers - Story Maps - Story Walls -

2. Compose

- Fill-in-the-Blank Activities - Provide students with blanks in which they are to fill-in with creative words/ideas. For example: If I were an animal, I would be a because ...This is what I would look like. (Illustration)

- Specificity - Provide students with specific information/questions to be answered that you want to be included in certain paragraphs. For example:

"The Run Away Hot Air Balloon"

Paragraph One:

1. Tell about the hot air balloon.

2. Describe the hot air balloon.

3 . Where is the hot air balloon flying?

4. How does the hot air balloon get away?

Paragraph Two:

1. Where did the hot air balloon go?

2. Why did the hot air balloon go there?

3. What did it see when it got there?

4. Tell about an exciting adventure your hot air balloon had.

5. How does your hot air balloon make it safely back home?

- Paragraph Starters - Provide students with the start of each paragraph, but encourage them to creatively complete each of the paragraphs. For example: "Once upon a time..." "First..." "Next..." "Then..." "At last..."

3. Evaluate

- Reflection Periods

- Peer-to-Peer Conference Times

- Teacher-Student Conference Times - Encourage them to find their mistakes. Praise them for their strengths. 
4. Revise

- COPS Editing Strategy - Capitalization (Are the first words in each sentences as well as the proper names capitalized?); Overall (How is the overall appearance of my writing - spacing, neatness, indentation of paragraphs, etc?); Punctuation (Is the punctuation correct?); Spelling (Are all the words spelled correctly?)

- Self-Assessment Checklist - This checklist is completed by the student. It may include the following types of questions: Do I have a beginning, middle, and ending? Did I use complete sentences? Does each sentence begin with a capital letter? Does each sentence end with correct ending punctuation? Did I use my neatest handwriting?

Resources Available:

COPS Strategy - SPELT: A Strategies Program for Effective Learning and Thinking by Mulcahy, Marfo, and Peat (1984)

How to Write a Story 1-3 by Evan Moor (2001)

Marvelous Month-by-Month Writing Prompts by Justin McCory Martin (2001) 


\section{Session Three - Creative Writing Across-the-Curriculum}

Anticipatory Set:

"Boxes" Object Lesson - Display several tiny boxes hypothetically filled with creative ideas and successful teaching strategies. Next, display one large box which represents an integrated approach to teaching. Explain that while the smaller boxes accomplish individual goals, the non-compartmentalized approach leads to greater success in the classroom.

Key Points:

Writing is a not to be taught as a separate subject. It should be included in all parts of the curriculum as a means of enhancing the learning process across the board. Emphasis the success of integrated units!

Strategies/Techniques to Discuss:

- Reading (“Charlotte's Web” Novel Study) - Write \& present a play depicting a scene from the book.

- Spelling - Using ten of your list words, write a rap and perform it for the class.

- History/Social Studies (French Revolution) - "If you had lived during the French Revolution, would you have sided with the King or with the common people?" Why? Record your answer in your History/Social Studies Journal, and then be prepared to share aloud.

- Science (Human Body Unit) - Write a letter to your friend telling them as many interesting facts about the human body as you can.

- Science - "How would your life change if the sun disappeared? Record your answer in your Science Journal, and then be prepared to share aloud.

- Math - Write a letter to a friend explaining how to solve a particular type of math problem. 
Integrated Unit - “Charlotte's Web” [Example: Third-Grade]

1. Science Report on Spiders

2. Puppet Show Script - Representing One Specific Scene from the Book

3. Venn Diagram - Contrast/Comparison of Wilbur and Charlotte

4. Student Journal - Including the Main Idea(s)/Vocabulary Words from each chapter

5. Spider Web - Designed by the student (w/ yarn) - Displaying the word "Humble"

6. Humility Essay

7. Pencil Sketch of Templeton

8. "Fern's Diary" - Including 5 Entries (Depicting her Feelings/Emotions throughout the book)

9. Map of the Fair

10. Birth Announcement - Announcing the Birth of Charlotte's Babies 11. Diorama (Representing the Barn Cellar)

Resources Available:

Writing Lessons Using the Multiple Intelligences by Teacher Created Resources (2002)

Content Area Reading, Writing, and Storytelling by Brian Ellis - Teacher Ideas Press (2008) 
Session Four - Creative Writing for the Holidays

Anticipatory Set: [Decorate conference room for a variety of different holidays.]

Key Points: Including additional creative writing activities in holiday celebrations makes for an exciting atmosphere.

Strategies/Techniques to Discuss:

- New Year's Day - New Year's Resolutions: "I will...” (Writing Complete Sentences)

- Valentine's Day - Write a love song to Jesus. (Song-Writing)

- President's Day - Write a letter to the president. (Letter Writing)

- St. Patrick's Day - Following the read aloud of a related book, summarize the history of St. Patrick's Day. (Main Idea/Gist)

- Easter - Answer the question, "How would things be different if Jesus had not risen from the dead?" (Critical Thinking/Essay)

- Mother's Day - Draw a flower and on each petal, write a word that describes your mom. (Descriptive Words - Adjectives)

- Independence Day - Write a haiku about our country's flag. (Poetry)

- Thanksgiving - Imagine that you are traveling to America aboard the Mayflower. For five days, journal your exciting adventure if your notebook. (Journaling)

- Christmas - Read Luke 2. Rewrite it in your own words. (Summarizing)

- Holiday Read-Alouds (Christmas Examples - The Gingerbread Man, The Christmas Alligator, etc.) - Following the read-aloud, instruct the students to write creatively in one of the following ways:

- What do they think will happen next? (Predicting)

$\circ$ If you could change the ending to this story, what would it be? (Critical Thinking)

- Would you have reacted the same way in which the character(s) in the story did? Why or why not? (Critical Thinking)

Resources Available:

Marvelous Month-by-Month Writing Prompts by Justin McCory Martin (2001)

Creative Writing Made Easy Holidays by Rusty Fischer - Good Apple, Inc (1998)

Just Write for the Holidays by Marji E. Gold-Vukson (1993) 
POWER POINT PRESENTATION

Slide 1

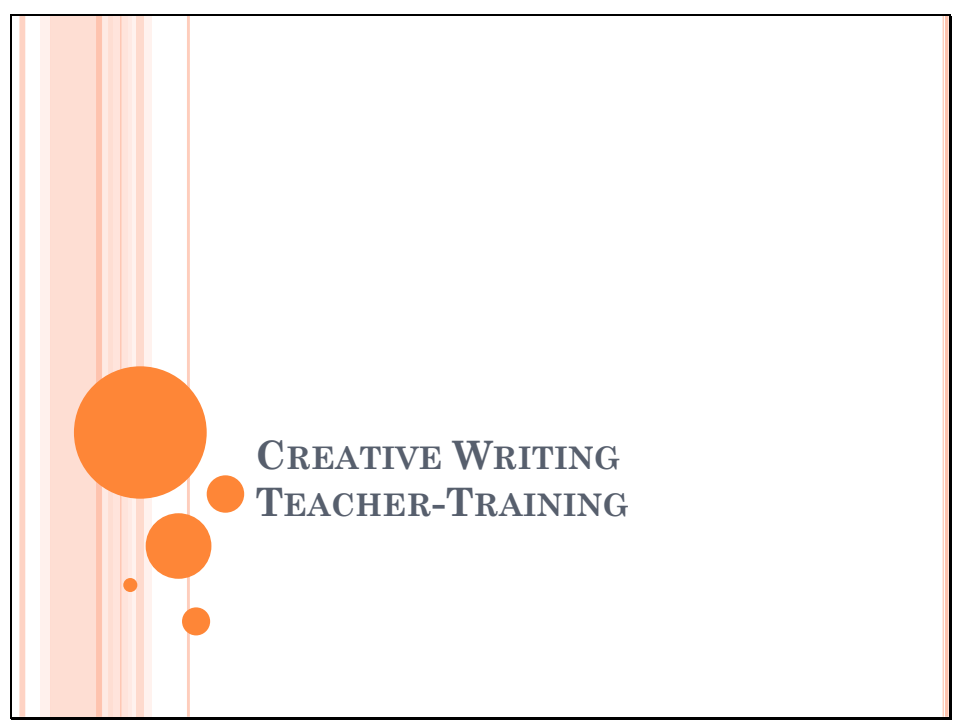


Slide 2

Teachers' Perceptions of Creative WRITING INSTRUCTION

- Always make time for writing. Do not ever treat it as an "extra".

- Establish an exciting mood during writing time.

- Model strong creative writing skills.

- Expose students to all genres of writing.

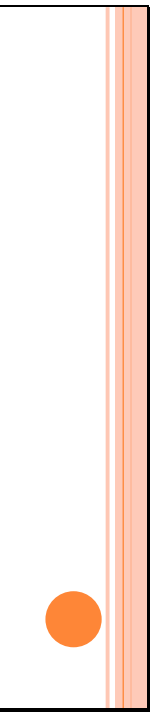


Slide 3

Teachers' Perceptions of Creative WRITING INSTRUCTION

- Provide the students with opportunities to write as a group.

- Portfolios - Provide each child with a portfolio (folder, box, etc.) in which to keep their published works.

- Invite a published author to join the class and share their product(s) with the students. 
Slide 4

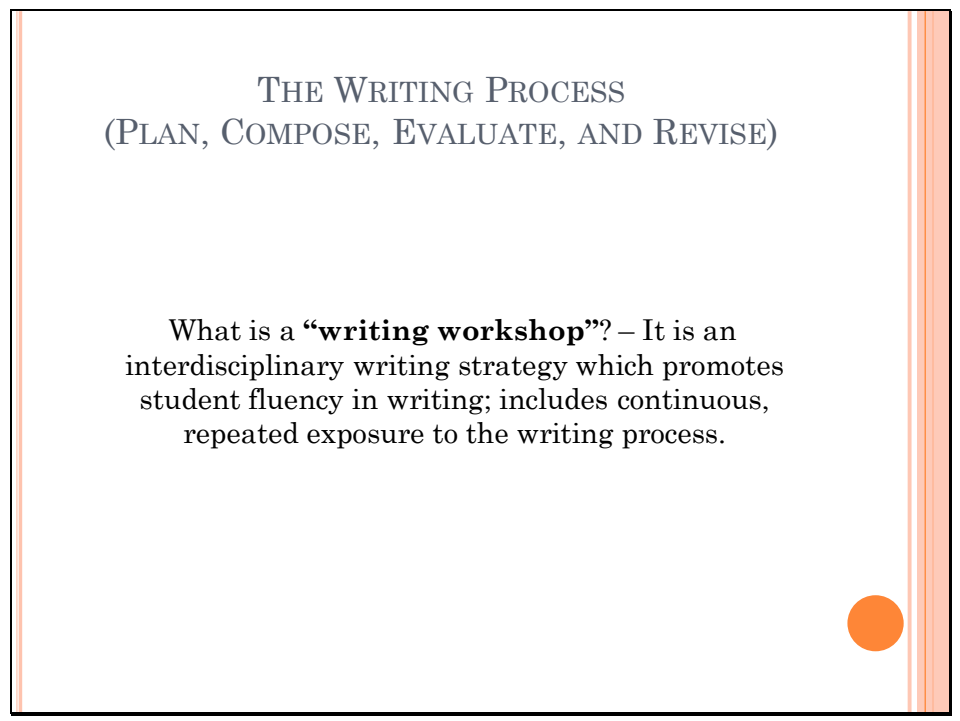


Slide 5

The Writing Process
(Plan, Compose, Evaluate, AND REvise)
Plan - Brainstorming
$\circ$ Idea Basket
$\circ$ Subject Jar
$\circ$ Story Starters
$\circ$ Picture Prompts
$\circ$ Free Writing


Slide 6

\begin{tabular}{c} 
The Writing Process \\
(Plan, Compose, Evalute, AND Revise) \\
Plan - Organizing \\
$\circ$ Hamburger Writing \\
$\circ$ Write a Story 1, 2, 3 \\
Graphic Organizers \\
\hline
\end{tabular}


Slide 7

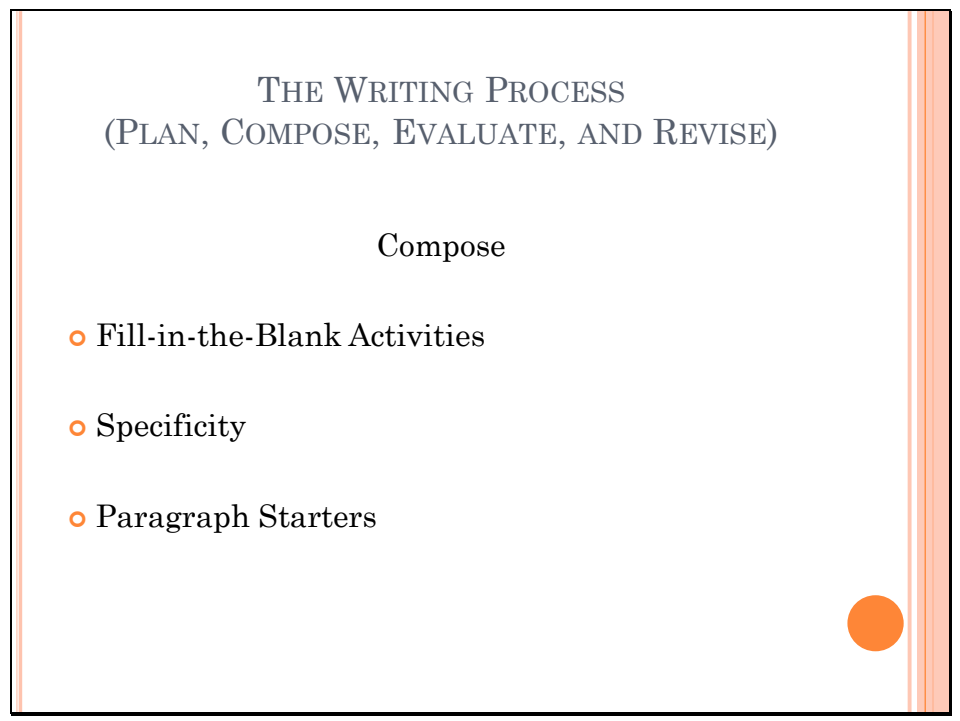


Slide 8

\begin{tabular}{c} 
The Writing Process \\
(Plan, Compose, Evalute, And Revise) \\
Evaluate \\
. Reflection Periods \\
. Peer-to-Peer Conference Times \\
Teacher-Student Conference Times \\
\hline
\end{tabular}


Slide 9

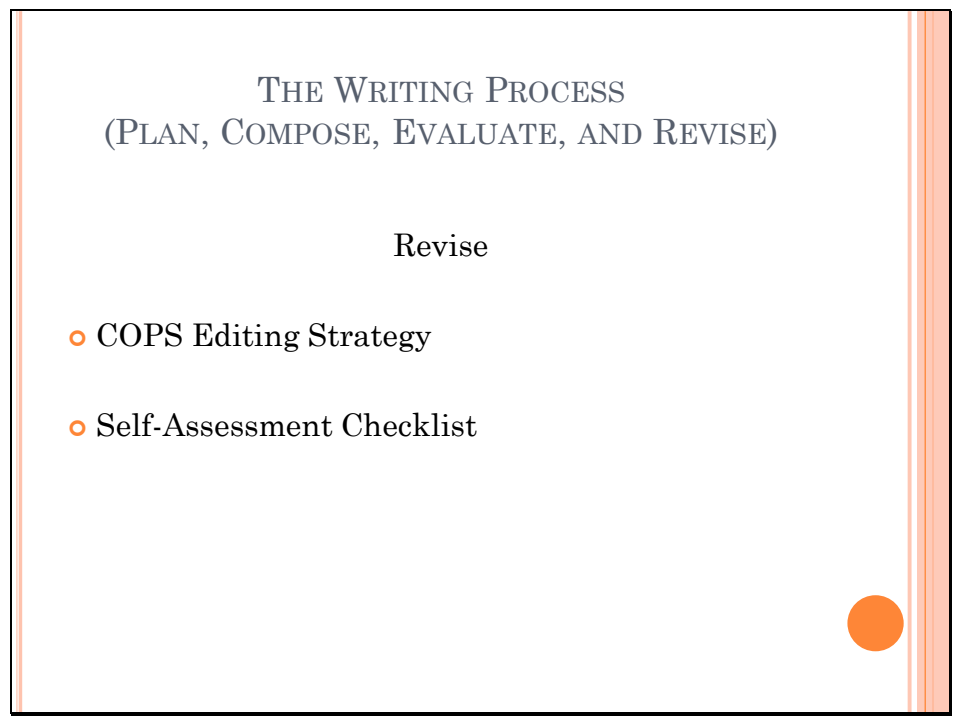




\section{Slide 10}

\section{Creative Writing ACROSS-THE-CURRICULUM}

- History/Social Studies (French Revolution) - "If you had lived during the French Revolution, would you have sided with the King or with the common people?" Why? Record your answer in your History/Social Studies Journal, and then be prepared to share aloud.

- Science (Human Body Unit) - Write a letter to your friend telling them as many interesting facts about the human body as you can.

- Science - "How would your life change if the sun

disappeared? Record your answer in your Science Journal, and then be prepared to share aloud.

- Math - Write a letter to a friend explaining how to solve a particular type of math problem.

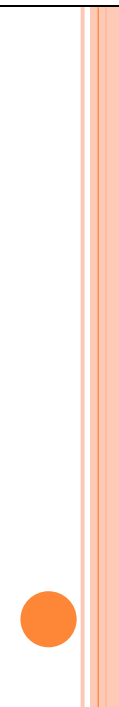




\section{Slide 11}

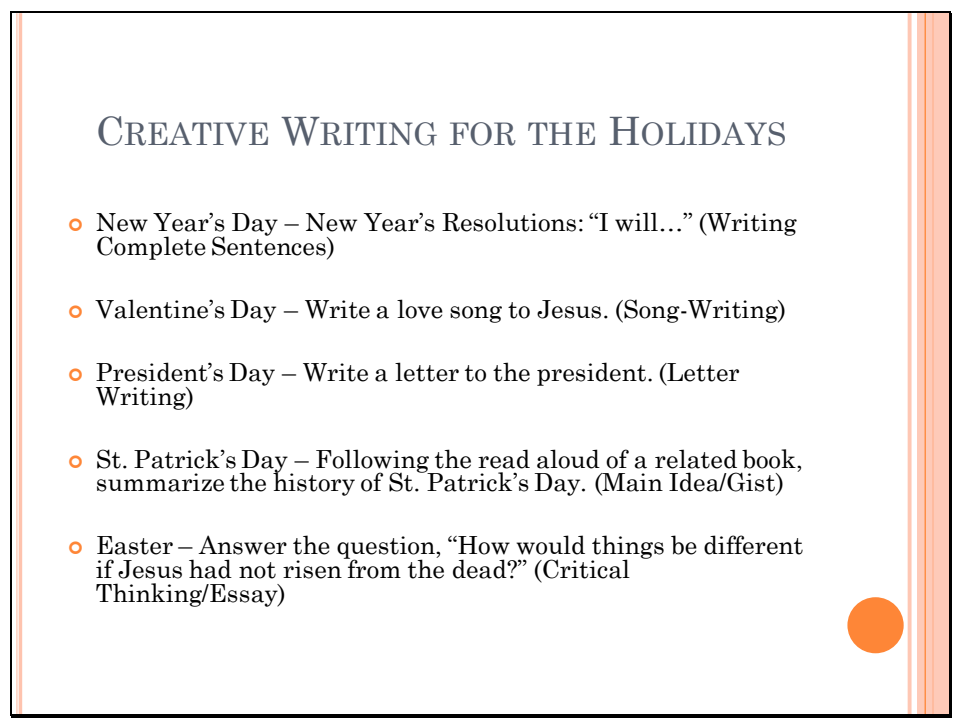




\section{Slide 12}

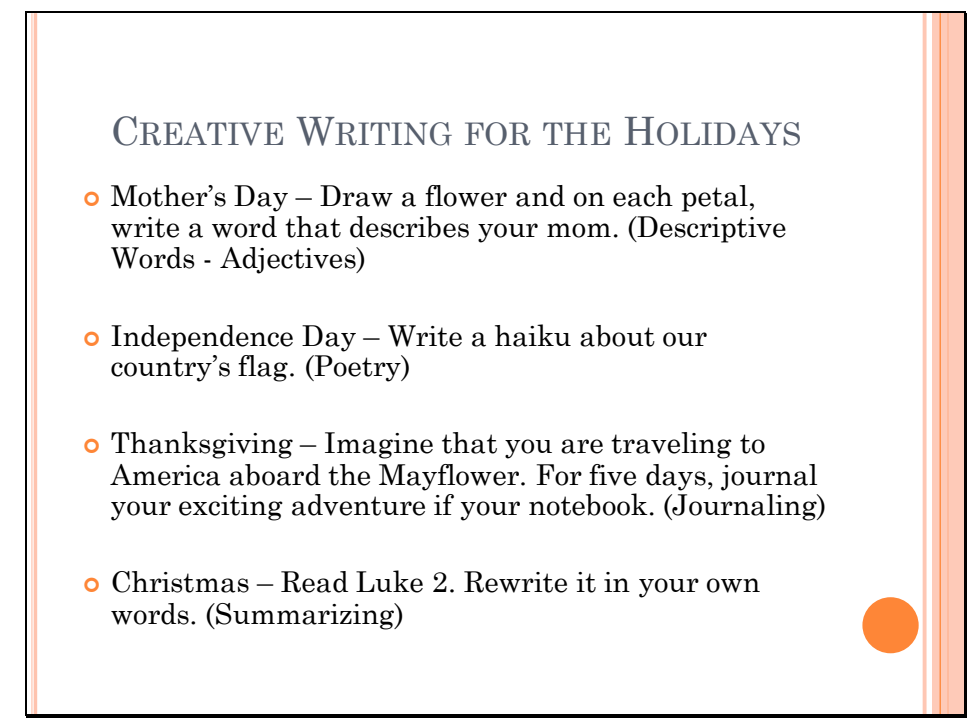




\section{APPENDIX C "STRATEGY PACKET"}

Session One: Teachers' Perceptions of Creative Writing Instruction

- Always make time for writing. Do not ever treat it as an "extra".

- Establish an exciting mood during writing time.

- Model strong creative writing skills. Teachers must also be open, honest, and "real" in their writing if they expect their students to do the same. Creative writing instructors should write-along as their students write. What a wonderful example this is for students!

- Expose students to all genres of writing. Assist them in becoming comfortable with varying styles.

- Provide the students with opportunities to write as a group. Their enthusiasm will be contagious. (Students must be taught to value and respect individual differences.)

- Portfolios - Provide each child with a portfolio (folder, box, etc.) in which to keep their published works. As this collection builds, so will their confidence as they begin to understand that you value their creative work.

- Invite a published author to join the class and share their product(s) with the students. 
Session Two: The Writing Process (Plan, Compose, Evaluate, and Revise)

Plan

a. Brainstorming

- Idea Basket - Fill a small basket with a variety of items. This could be a themed basket or it could include a wide range of random objects. Instruct each student to choose one item from the basket and write about it.

- Subject Jar - Fill a jar with strips of paper that include a variety of different things that have to do with a particular topic. For example, if the topic is "winter", the strips will say things like "snowman", "chicken noodle soup", "polar bear", mittens", etc. Allow students to pull a strip from the jar and write a descriptive paragraph about their chosen object.

- Story Starters - Writing prompts provide students with interesting ideas as a means of getting their creative juices flowing.

- Picture Prompts - Display a random picture/photograph, and instruct the students to create a story about the picture.

- Free Writing - Allowing students to write freely about a particular topic provides them with an incredible opportunity to brainstorm. Mechanics should not to be the focus during "free writing".

b. Organizing

- Hamburger Writing - Top Bun (Beginning/Topic Sentence); Meat (Middle/Supporting Detail Sentences); and Bottom Bun (Ending/Conclusion Sentence)

- Write a Story 1, 2, 3- Paragraph One includes the characters and the setting (Who? Where? When?). Paragraph Two includes the action (What happened?). Paragraph Three includes the conclusion (What happened last? How did the story end?)

- Graphic Organizers - Story Maps - Story Walls - 


\section{Compose}

- Fill-in-the-Blank Activities - Provide students with blanks in which they are to fill-in with creative words/ideas. For example: If I were an animal, I would be a because ...This is what I would look like. (Illustration)

- Specificity - Provide students with specific information/questions to be answered that you want to be included in certain paragraphs. For example:

Paragraph One:

"The Run Away Hot Air Balloon"

1. Tell about the hot air balloon.

2. Describe the hot air balloon.

3 . Where is the hot air balloon flying?

4. How does the hot air balloon get away?

Paragraph Two:

1. Where did the hot air balloon go?

2. Why did the hot air balloon go there?

3. What did it see when it got there?

4. Tell about an exciting adventure your hot air balloon had.

5 . How does your hot air balloon make it safely back home?

- Paragraph Starters - Provide students with the start of each paragraph, but encourage them to creatively complete each of the paragraphs. For example: "Once upon a time..." "First..." "Next..." "Then..." "At last..."

Evaluate

- Reflection Periods

- Peer-to-Peer Conference Times

- Teacher-Student Conference Times - Encourage them to find their mistakes. Praise them for their strengths. 
Revise

- COPS Editing Strategy - Capitalization (Are the first words in each sentences as well as the proper names capitalized?); Overall (How is the overall appearance of my writing - spacing, neatness, indentation of paragraphs, etc?); Punctuation (Is the punctuation correct?); Spelling (Are all the words spelled correctly?)

- Self-Assessment Checklist - This checklist is completed by the student. It may include the following types of questions: Do I have a beginning, middle, and ending? Did I use complete sentences? Does each sentence begin with a capital letter? Does each sentence end with correct ending punctuation? Did I use my neatest handwriting? 
Session Three: Creative Writing Across-the-Curriculum

- Reading (“Charlotte's Web" Novel Study) - Write \& present a play depicting a scene from the book.

- Spelling - Using ten of your list words, write a rap and perform it for the class.

- History/Social Studies (French Revolution) - "If you had lived during the French Revolution, would you have sided with the King or with the common people?" Why? Record your answer in your History/Social Studies Journal, and then be prepared to share aloud.

- Science (Human Body Unit) - Write a letter to your friend telling them as many interesting facts about the human body as you can.

- Science - "How would your life change if the sun disappeared? Record your answer in your Science Journal, and then be prepared to share aloud.

- Math - Write a letter to a friend explaining how to solve a particular type of math problem.

- Integrated Unit - "Charlotte's Web" [Example: Third-Grade]

1. Science Report on Spiders

2. Puppet Show Script - Representing One Specific Scene from the Book

3. Venn Diagram - Contrast/Comparison of Wilbur and Charlotte

4. Student Journal - Including the Main Idea(s)/Vocabulary Words from each chapter

5. Spider Web - Designed by the student (w/ yarn) - Displaying the word "Humble"

6. Humility Essay

7. Pencil Sketch of Templeton

8. "Fern's Diary" - Including 5 Entries (Depicting her Feelings/Emotions throughout the book)

9. Map of the Fair

10. Birth Announcement - Announcing the Birth of Charlotte's Babies

11. Diorama (Representing the Barn Cellar) 
Session Four: Creative Writing for the Holidays

- New Year's Day - New Year's Resolutions: “I will...” (Writing Complete Sentences)

- Valentine's Day - Write a love song to Jesus. (Song-Writing)

- President's Day - Write a letter to the president. (Letter Writing)

- St. Patrick's Day - Following the read aloud of a related book, summarize the history of St. Patrick's Day. (Main Idea/Gist)

- Easter - Answer the question, "How would things be different if Jesus had not risen from the dead?" (Critical Thinking/Essay)

- Mother's Day - Draw a flower and on each petal, write a word that describes your mom. (Descriptive Words - Adjectives)

- Independence Day - Write a haiku about our country's flag. (Poetry)

- Thanksgiving - Imagine that you are traveling to America aboard the Mayflower. For five days, journal your exciting adventure if your notebook. (Journaling)

- Christmas - Read Luke 2. Rewrite it in your own words. (Summarizing)

- Holiday Read-Alouds (Christmas Examples - The Gingerbread Man, The Christmas Alligator, etc.) - Following the read-aloud, instruct the students to write creatively in one of the following ways:

- What do they think will happen next? (Predicting)

- If you could change the ending to this story, what would it be? (Critical Thinking)

- Would you have reacted the same way in which the character(s) in the story did? Why or why not? (Critical Thinking) 


\section{Creative-Writing Seminar Questionnaire}

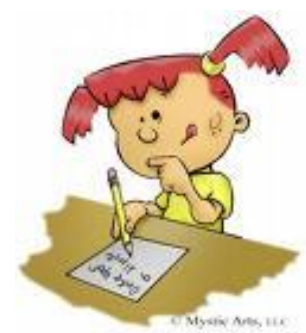

Your Name

School

Grade Level

As an educator, did your perception(s) of creative writing instruction change as a result of this session?

If so, how?

What practical strategies did you gain from your attendance to this seminar? 
Do you intend to utilize any of these new ideas into your classroom instruction?

If so, please describe your plan for implementation?

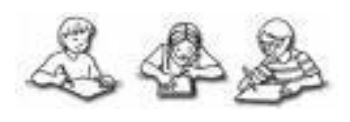

An incentive will be provided for each teacher who not only completes and returns the questionnaire but who [within the next thirty days] implements at least one new creative writing technique into their instruction. Upon the completion of doing so, please e-mail me personally and describe not only the strategy that was carried out but also the result of your doing so.

Contact Information:

Elizabeth Rice

earice@cedarville.edu 